\title{
Incomplete Information Bargaining with Outside Opportunities
}

\section{Citation}

Fudenberg, Drew, David K. Levine, and Jean Tirole. 1987. Incomplete information bargaining with outside opportunities. Quarterly Journal of Economics 102, no. 1: 37-50.

\section{Published Version}

http://dx.doi.org/10.2307/1884679

\section{Permanent link}

http://nrs.harvard.edu/urn-3:HUL.InstRepos:3196301

\section{Terms of Use}

This article was downloaded from Harvard University's DASH repository, and is made available under the terms and conditions applicable to Other Posted Material, as set forth at http:// nrs.harvard.edu/urn-3:HUL.InstRepos:dash.current.terms-of-use\#LAA

\section{Share Your Story}

The Harvard community has made this article openly available.

Please share how this access benefits you. Submit a story.

Accessibility 


\title{
INCOMPLETE INFORMATION BARGAINING WITH OUTSIDE OPPORTUNITIES*
}

\author{
DREW FudenBERG \\ DAVID K. LEVINE \\ JEAN TIROLE
}

\begin{abstract}
We consider two kinds of "outside opportunity" that a seller of an indivisible good might have: selling to a different buyer and consuming the good herself. In both models the seller is uncertain about the buyer's valuation, and becomes more pessimistic over time. When the seller becomes sufficiently pessimistic, she prefers the outside opportunity, so she will not bargain indefinitely with the current buyer. Despite the resulting finite-horizon nature of negotiations, the link between the buyer's willingness to accept an offer and the seller's eagerness to go "outside" generates multiple equilibria.
\end{abstract}

\section{INTRODUCTION}

We consider two kinds of "outside opportunity" that a seller of an indivisible good might have in addition to the "inside opportunity" of selling to the buyer with whom she is currently bargaining: selling to a different buyer and consuming the good herself. In both models the seller is uncertain about the buyer's valuation, and becomes more pessimistic over time. When the seller becomes sufficiently pessimistic, she prefers the outside opportunity, so she will not bargain indefinitely with the current buyer. Despite the resulting finite-horizon nature of negotiations, the link between the buyer's willingness to accept an offer and the seller's eagerness to go "outside" generates multiple equilibria. Consequently, the outside opportunity in our model has a very different effect than in the complete information models of Binmore-Rubinstein-Wolinsky [1985] and Shaked-Sutton [1984].

In the many-buyer model the seller bargains with one buyer at a time, and makes all the offers. At any time the seller may break off negotiations in order to bargain with someone else. We use this highly stylized model to make a fairly general observation: with many buyers the seller's reservation value exceeds her consumption value, so that she need not continue to negotiate with a buyer even when it is common knowledge that there are gains from trade between them. In addition, we show in Section III, if the seller can

*We would like to thank Eric Maskin and the referees for helpful comments on an earlier draft. Financial support from the National Science Foundation Grants SES84-09877 and SES85-09484, and the UCLA Academic Senate is gratefully acknowledged.

(1) 1987 by the President and Fellows of Harvard College and the Massachusetts Institute of 
costlessly switch buyers, the outside opportunity may allow the seller to commit to a fixed price.

When the seller can costlessly switch buyers, the credible take-it-or-leave-it price she sets is quite generally the same one the seller would charge could she commit herself to any desired pricing path. In this equilibrium the seller switches buyers over time. Depending on the parameters, there may also exist an equilibrium in which the seller charges a price that is certain to be accepted, and does not switch buyers if this price is unexpectedly refused. The multiplicity of equilibria can be thought of as due to an externality between the different buyers: if future buyers will play "soft," i.e., are likely to accept high prices, the seller is likely to switch buyers, and thus the current buyer should also accept a high price. On the other hand, if future buyers will play "tough," the seller is less likely to switch, so the current buyer can play tough as well.

The seller always prefers to face many buyers, while each buyer would prefer to be the only trading partner. More surprisingly, depending on which equilibrium prevails with many buyers, total expected surplus may decrease in moving from one to many buyers, even though the total potential surplus is increased. Thus, given that there are many potential buyers, total surplus can sometimes be increased by requiring the seller to negotiate with only one of them. Further, we find that with many buyers the effects of shrinking the time period between offers to zero enables the seller to appropriate all the surplus-in contrast to the one-buyer model in which a shorter time period transfers more of the surplus to the buyers. ${ }^{1}$ With many buyers and a short time period the seller can easily extract all potential surplus by switching buyers.

In Section IV we consider the case in which the seller faces an additional delay cost in switching buyers. Because of this cost the seller must become sufficiently pessimistic before switching buyers, so that the take-it-or-leave-it strategy may not be credible. In this case the equilibrium may involve "haggling": the seller initially makes a high offer; if this offer is refused, the seller's equilibrium payoff drops, but she follows with a lower offer to the same buyer before switching. We give an example of haggling equilibrium that has the same price path as the "tough seller" equilibrium that Fudenberg-Tirole [1983] derived in a model with one buyer and two periods. Our model is a hybrid of finite and infinite-horizon

1. This is the Coase conjecture. For a discussion see Coase [1972], Stokey [1980], Bulow [1982], or Gul-Sonnenschein-Wilson [1985]. 
bargaining, in that it allows traders to continue bargaining indefinitely, but results in negotiations of finite length. However, we should not overstress the analogy with the two-period model, because the number of equilibria and the comparative statics can differ.

Finally, Section V considers the model of a seller who faces only one buyer, but can consume the good herself. Once again the seller's decision of when to use her outside opportunity allows us to construct multiple equilibria. In our example, in one equilibrium, the seller consumes in the second period; while in the other, she makes a second offer. The "early consumption" equilibrium corresponds to the "always switch" equilibrium in the many-buyers model. Indeed, play between the seller and an individual buyer in the always-switch equilibrium is exactly as if the "switch" option were replaced by a consumption option of the same value. Our results imply that there are also multiple equilibria in the pricediscrimination model of Stokey [1980], Bulow [1982], and GulSonnenschein-Wilson [1985] if the monopolist has an opportunity cost of producing in this market, or can sell its product for scrap at a known price.

\section{The Multi-Buyer Model}

The seller has a single indivisible object for sale. The seller derives no utility from having the object in her inventory, and storage is costless. It is common knowledge that the seller's valuation is zero. There are an infinite number of ex ante identical buyers. Each buyer's valuation $b$ is known only to him. The buyer's valuations are independently and identically distributed on the interval $[\underline{b}, \bar{b}], \underline{b}>0$, according to the cumulative distribution function $\bar{F}(b)$, which is common knowledge. Additional assumptions on $F$ are discussed below. The seller and all buyers have discount factors $\delta_{S}, \delta_{B}$, respectively.

Time is indexed by periods $t=1, \ldots$ At time 1 the seller begins to bargain with the first buyer by naming a price that the buyer may accept or reject. If the buyer rejects, the seller has the choice of making a second offer to the same buyer in period 2, or to break off negotiations with this buyer and begin negotiations with another. If the seller does choose to switch buyers, she must wait a lag of $d$ ("delay") periods before making her next offer. If $d=0$, the seller can make an offer to the second buyer in period 2, so that switching 
is costless. Thus, the seller makes all the offers, and the seller cannot negotiate with several buyers at once. We assume that the seller cannot recall a buyer once having passed on to a new one.

One feature of this game is the fact that the buyer does not make any offers. It may therefore be regarded as an extension of the infinite-horizon one-sided bargaining game studied by Sobel and Takahashi [1983], and Fudenberg, Levine, and Tirole [1985a], to the case in which there are many buyers. If $d=\infty$, the games are the same.

A perfect Bayesian equilibrium of our game is a (historycontingent) sequence of prices and switching decisions for the seller, of buyers' acceptances or refusals of the offers, and of (updated) beliefs about the buyers' valuations satisfying the usual optimality conditions and Bayes rule. This solution concept is a weaker version of the sequential equilibrium of Kreps-Wilson [1982] which is not defined for games with a continuum of actions.

A useful fact about equilibrium is

LEMMA 1 (Successive Skimming). In any perfect Bayesian equilibrium, at any time, the seller's posterior about the valuation of the current buyer is the seller's prior truncated at some value $\beta$; i.e., the posterior is $F(b) / F(\beta)$ for $b \leqslant \beta$, and 1 for $b \geqslant \beta$.

Proof. Omitted; see Fudenberg-Levine-Tirole [1985a]. The lemma follows from the "incentive-compatibility" constraints and the fact that high-value buyers lose more by waiting than low-value ones do.

In this paper we shall restrict attention to those perfect Bayesian equilibria that are stationary and monotone. By stationarity we mean that the strategies used by the seller and the current buyer can depend only on events that have occurred since this particular buyer arrived. Furthermore, if the seller's beliefs about the buyer do not change from one period to the next, then her offer does not change, either. By monotonicity we mean that the seller's (expected) equilibrium payoff at the beginning of a period strictly decreases as the sellers' beliefs about the current buyer become more pessimistic; i.e., as the truncation point $\beta$ decreases.

We should point out that if the seller is restricted to strategies that depend only on her current beliefs, and the buyer to strategies that depend only on his value and the seller's latest offer, then the equilibrium is stationary (obviously) and monotone. Since the 
buyers who choose to buy depend only on the latest offer, by successive skimming, any pricing strategy charging more than $\underline{b}$ (and not always rejected) yields strictly more if the cutoff point on beliefs $\beta$ is larger. Since rejection of the type of offer considered above (which exceeds $b$ and is not rejected by everyone) strictly lowers the prior $\beta$, the equilibrium is monotone.

\section{No DeLAY CostS}

This section analyzes the case in which switching buyers is not costly, so that $d=0$. We also assume that the cumulative distribution function of buyers, $F(b)$, is twice continuously differentiable. We show that, depending on the parameters, there are at most two possible payoffs for the seller in a stationary, Monotone equilibrium, namely, (i) $\underline{b}$ and (ii) the payoff when the seller can commit herself to a single take-it-or-leave-it price. The latter is always an equilibrium payoff; the former requires that $\underline{b}$ be sufficiently large, and, in particular, does not exist if $\underline{b}$ equals the seller's valuation of zero. We proceed by constructing equilibria that yield these two payoffs and then show that no other payoffs can arise in equilibrium. We then compare the equilibria to the one-buyer case.

\section{A. No-Switching Equilibrium}

In this equilibrium the seller charges $\underline{b}$ each period regardless of the history of the game, and the seller never switches away from the current potential buyer. The buyer of valuation $b$ thus accepts all offers $p$ less than or equal to $\left(1-\delta_{B}\right) b+\delta_{B} \underline{b}$, so the seller's posterior after an offer of $p$ is refused is $\beta(p)=\left(p-\delta_{B} \underline{b}\right) /\left(1-\delta_{B}\right)$. A necessary condition for this equilibrium is that the seller does not wish to choose a price above $\underline{b}$, given that $\underline{b}$ is expected next period:

$$
\underline{b} \geq \max _{p}\left[p(1-F(\beta(p)))+\delta_{S} F(\beta(p)) \underline{b}\right] .
$$

Condition (1) is also sufficient. In a no-switching equilibrium, buyers expect $\underline{b}$ next period and so will accept an offer if and only if $b \geq \beta(p)$. Given this, (1) says that it is best for the seller to charge $\underline{b}$ right now.

\section{B. Switching Equilibrium}

In this equilibrium the seller announces that she will charge a single take-it-or-leave-it price $\hat{p}$ to each buyer, and switch buyers 
until $\hat{p}$ is accepted. The buyer of valuation $b$ accepts all prices less than or equal to $b$. The price $\hat{p}$ is chosen to be the "precommitment" price the seller would choose if she could precommit herself to a take-it-or-leave-it price. The fact that $\hat{p}$ is the seller's equilibrium choice without precommitment, but with the buyers playing "truthfully," should be intuitive. Since the seller always switches buyers, her choice problem is stationary, so from dynamic programming we know that the single-period and multi-period optimizations are identical. Formally, let $V_{S}$ be the seller's value without precommitment, and let $V_{S}^{c}$ be the seller's value with precommitment:

$$
\begin{aligned}
V_{S} & =\max _{p}\left[(1-F(p)) p+F(p) \delta_{S} V_{S}\right] \\
V_{S}^{c} & =\max _{p} \sum_{t=0}^{\infty}(1-F(p)) p\left(F(p) \delta_{S}\right)^{t} \\
& =\max _{p}(1-F(p)) p+\delta_{S} F(p) V_{S}^{c}
\end{aligned}
$$

Since $V_{S}$ and $V_{S}^{c}$ satisfy the same necessary and sufficient functional equation, they have the same solution(s).

Lemma 2. If $F^{\prime \prime}(p) \geq 0$, the price that solves (2) is unique.

Proof. A simple calculation.

We conclude that the precommitment price(s) are always equilibrium outcomes. Moreover, we can show that if the seller can precommit herself to any time path of prices, her optimal strategy is to charge a fixed price. Riley and Zeckhauser [1983] prove a similar result in a related context. In outline, the optimal precommitment strategy is to always switch buyers. This has two effects: it maximizes the buyers' reservation values $\beta(p)$ for every price path; and it also means that every period the seller faces the most favorable distribution of buyer valuations. Because the seller always switches, her maximization problem is stationary. Thus, a constant price is optimal.

A necessary and sufficient condition for the precommitment price to strictly exceed $\underline{b}$ is

$$
\max _{p} p(1-F(p))+\delta_{S} F(p) \underline{b}>\underline{b} .
$$

This condition overlaps with condition (1), the sufficient condition for a no-switching equilibrium with price $\underline{b}$. The best price may be $\underline{b}$ when buyers expect to face $\underline{b}$ next period; but if buyers expect the seller to switch, their reservation value rises to their valuation, and 
the return to the seller for charging prices above $\underline{b}$ increases. Thus, for a range of parameter values the "best possible" and "worst possible" outcomes, from the point of view of the seller, can occur. The multiplicity arises from the feedback between the seller's switching decision and buyers' reservation values, and is a general feature of many-player bargaining. ${ }^{2}$

\section{Characterization of Stationary Monotone Equilibria}

The "no-switching" and "full switching" equilibria by no means exhaust the list of possibilities. There can be "semiswitching" equilibria in which the seller randomizes over the switching decision. However, we can show that these two types of equilibria generate all stationary monotone equilbrium valuations for the seller; that is, either $V_{S}=\underline{b}$, or $V_{S}=V_{S}^{c}$.

First, we observe that we must have $V_{S} \geq \underline{b}$, since the seller can always charge $b$ which will be accepted. (This can be proved by a straightforward extension of Lemma 2 of Fudenberg-Levine-Tirole [1985a].) Next, we claim that in any stationary monotone equilibrium, if $V_{S}>\underline{b}$, then the seller always switches buyers. If the seller were not to switch when price $p_{t}$ was refused in period $t$, the value of continuing with the old buyer would have to be at least as great as that of facing a new one. But if $p_{t}$ is refused with probability strictly between zero and one, by monotonicity the seller is worse off sticking with the old buyer than she was before the offer was rejected; and by induction worse off than when she first met the old buyer. However, by stationarity, the new buyer is as good as the old one was initially. Thus, either $p_{t+1}=b=V_{S}$, or $p_{t}$ is refused with probability one. The latter is impossible, for if the seller makes an offer that everyone refuses, her beliefs do not change and she must make the same offer again. Subsequently it must be rejected again, and the seller's present value is zero, which contradicts $V_{s} \geq b$.

We have thus established

Proposition 1. If delay costs are zero, then either $V_{S}=\underline{b}$, or $V_{S}=$ $V_{S}^{c}$, the precommitment value. For certain parameter values both are equilibrium payoffs. For $b$ sufficiently small, there

2. Some readers may be puzzled by the fact that in always-switch equilibrium, some buyers bargain when they know that they will not be able to trade. One justification is that, without "entry" costs, receiving an offer is a weakly dominant strategy. If all buyers had positive entry costs, then low-valuation buyers would never enter; knowing this, the seller would set a higher price, which would deter still more buyers and the equilibrium would unravel as discussed in Fudenberg-LevineTirole [1985a, Sec. 5.5]. This unraveling could be avoided and the always-switch equilibrium restored, if some buyers had negative "entry costs" because they enjoyed bargaining. 
exists a unique equilibrium. In this equilibrium the seller never haggles; i.e., she charges a fixed price and switches buyers in case of refusal.

We do not know whether there are nonstationary equilibria with other equilibrium payoffs.

\section{Comparison with a Single Buyer}

Next we compare the equilibrium outcomes with the case of a single buyer. The condition for an equilibrium with price $\underline{b}$, equation (1), is also necessary and sufficient for an equilibrium with price $b$ in the one-buyer case. Moreover, from Fudenberg-LevineTirole [1985a] we know that with $\underline{b}>0$ the one-buyer equilibrium is unique. Thus, when (1) is satisfied, the seller is at least as well off facing many buyers. When (1) is not satisfied, the one-buyer equilibrium will yield the seller a payoff greater than $b$. However, this value will not be greater than that if the seller could precommit to a price path against the single buyer, which in turn is not greater than the value when the seller can precommit against many buyers. Thus, again the seller is at least as well-off. Conversely, if $F^{\prime \prime}>0$, then a comparison of first-order conditions shows that the switching-equilibrium price is never less than that with one buyer. Consequently, each buyer prefers the seller to have no outside opportunities. This is very natural-the outside opportunities put the seller in a stronger bargaining position.

More surprising are the efficiency of the switching and the no-switching equilibria for parameter values such that both exist. We can show that, depending on the parameter values, either equilibrium can yield greater expected total surplus. As all buyers but the first have zero surplus in the no-switching equilibrium, this implies that the expected aggregate surplus may decrease in moving from one potential buyer to many of them, despite the fact that the "potential surplus" is larger with many buyers.

In Fudenberg, Levine, and Tirole [1985b] we constructed an example in which equilibrium expected surplus is indeed lower with many buyers. The example has identical discount factors $\delta_{S}=\delta_{B}=\delta$, with $\delta$ near 1 , and $F(b)$ uniform on the interval $[1, \vec{b}]$, with $\vec{b}=2-$ $\delta+\epsilon$. In this example both the switching equilibrium and the no-switching equilibrium exist, and the precommitment price $\hat{p}$ is just above the no-switching price of 1 . Thus, raising the price from 1 to $\hat{p}$ does not help the seller much, but it does hurt the buyers as a group, so the total expected surplus is lower at $\hat{p}$ than it would be at 
the no-switching equilibrium. It follows that total expected surplus is higher at the only equilibrium with one buyer (that is, the no-switching equilibrium), than it is at the switching equilibrium with many buyers.

It is much less surprising that expected surplus can be higher with many buyers. The easiest example is when $\delta=1$; that is, the periods are "short." In this case the seller's return to a fixed price $p$ is $p$ itself, so the seller charges $\bar{b}$, which equals the expected surplus. With just one buyer the maximum realizable surplus is the buyer's valuation $b$, and so the maximum expected surplus is the expectation of $b$.

So we conclude

Proposition 2. With no delay costs, the seller prefers facing many buyers; the current buyer prefers being the only buyer. Total expected surplus can be bigger or smaller with many buyers than with one.

\section{Delay Costs}

We now consider the case $d>0$, so that switching buyers imposes an extra delay cost on the seller. This cost means that the seller must become "sufficiently pessimistic" about the current buyer before she finds it worthwhile to switch, so that the "alwaysswitch" equilibrium exists for a smaller set of parameter values. The equilibrium path may require the seller to make $n>1$ offers to the same buyer before switching.

It remains true that if a no-switching equilibrium exists, it is the same as the equilibrium with only one buyer. However, the delay cost makes the seller less eager to switch, and thus the no-switching equilibrium exists for more values of the parameters. If we let $W_{S}(b)$ be the seller's valuation in the one-buyer equilibrium when the distribution is truncated to $[\underline{b}, b]$ (which exists and is unique from Proposition 1 of Fudenberg-Levine-Tirole [1985a]), then a necessary and sufficient condition for the existence of a no-switching equilibrium is that $\underline{b} \geq \delta_{S}^{d} W_{S}(\bar{b})$. If this condition is satisfied, then no matter how pessimistic the seller becomes, she will never prefer to switch rather than to charge $\underline{b}$ now. Conversely, if this condition is not satisfied, then after a sufficient number of rejections the seller will strictly prefer to switch (since from Fudenberg-Levine-Tirole we know that in the one-buyer equilibrium. the seller eventually charges $\underline{b}$ ). 
In the no-delay case the bargaining process has a very special outcome. When $\underline{b}$ is low, the equilibrium is unique with the seller always switching: there is no haggling. When $b$ is high, there are other equilibria in which the seller makes an intermediate offer and then either switches or lowers her price to $\bar{b}$. This is not haggling in the strict sense because the seller can do just as well by not offering the lower price.

In the delay case an example in which $P$ has finite support shows how delay costs can lead to strict haggling. In the example, $d=3, \delta_{S}=\delta_{B}=1 / 2$, and each buyer has one of three values: $\underline{b}$ very small $\left(1 / 32\right.$, say), $\hat{b}=1$, or $\bar{b}=5 / 2$ with prior probabilities, $\underline{\eta}_{0}=\hat{\eta}_{0}=$ $\bar{\eta}_{0}=1 / 3$. In equilibrium the seller first charges a new buyer $P_{L}^{-}=7 / 4>$ $\hat{b}=1$. If this is refused, she then charges price $\hat{b}=1$ to the same buyer. If this is also rejected, she switches buyers. Buyers $\hat{b}$ and $b$ reject offers exceeding their valuations and accept all others. Buyer $\bar{b}$ is indifferent between accepting $p_{L}$ now and accepting an offer equal to $\hat{b}$ tomorrow. He accepts any offer not exceeding $p_{L}$. (For what happens when off-the-equilibrium-path offers above $p_{L}$ are made, see Fudenberg-Levine-Tirole [1985b].) In an earlier version of this paper [1985b] we showed that this is an equilibrium and that the equilibrium is robust with respect to a small perturbation of the parameters. It may also be checked that it is stationary and monotone.

So we have obtained robust examples of equilibrium in which the seller haggles for a while, becomes pessimistic, and prefers to switch despite the delay cost.

Proposition 3 . With strictly positive but finite delay costs, the seller may haggle and switch.

Play between the seller and each buyer in the example is exactly that derived in the two-period, one-buyer, two-type model of Fudenberg-Tirole [1983] for the case of a tough seller. There, in the notation of this paper, the seller charged $p_{L}$ in the first period and then $\hat{b}$ in the second. The finite horizon that is exogenous in Fudenberg-Tirole is derived endogenously here by adding a third type $\underline{b}$. Finite-horizon bargaining models without outside opportunities have been criticized because players may stop bargaining when it is common knowledge that there are gains from trade between them. While this criticism is justified, we see that similar behavior can be expected with an infinite horizon if there are outside opportunities. 


\section{CONSUMPTION AS AN OUTSIDE OPPORTUNITY}

Here we develop a model of a different kind of "outside" opportunity, namely the seller's option to consume the good herself. This possibility can generate multiple equilibria, just as the switching decision did. In each case the buyers are willing to pay more when the seller is more likely to use the outside opportunity. This willingness in turn makes the seller more pessimistic after an offer is refused and thus justifies her eagerness to go "outside."

Following Gul-Sonnenschein-Wilson [1985], we can adapt the model to analyze price discrimination by a durable goods monopolist. Imagine that there are a continuum of "small" consumers indexed by their willingness to pay. In the price discrimination model, in each period, the seller makes a price offer. This price is then accepted only by buyers with a high willingness to pay. The bargaining model is applied by reinterpreting probabilities as fractions of the population. Direct consumption by the seller can then be interpreted as an alternative elastic demand, or more loosely as an opportunity cost. Then the multiplicity of equilibria can be attributed to "bandwagon effects": if most buyers purchase today, the seller will not choose to produce tomorrow, so that buyers should indeed purchase today.

We content ourselves with a simple example of the multiplicity of equilibria.

Assume that the buyer's valuation is uniformly distributed on the interval $[0,1]$, that the seller's consumption value is $1 / 4$, and that both players have discount factor $\delta=1 / 2$. We shall construct a "tough seller" equilibrium, in which the seller consumes in the second period, and a "soft seller" equilibrium, in which the seller does not consume until period 3 .

Define $\beta_{0}=3 / 8+8^{-1 / 2}$. When the seller's beliefs are uniform on $\left[0, \beta_{0}\right]$ and the buyers believe that the seller will consume next period, the seller is indifferent between consuming now and charging the optimal price $p_{0}=\beta_{0} / 2+1 / 16$. The tough-seller equilibrium has the following form: first-period price $p$ is accepted by all buyers with valuation at least $\beta^{*}(p)$, where

$$
\beta^{*}(p)= \begin{cases}p & 0 \leq p \leq \beta_{0} \\ 4 / 3 p-1 / 24 & \beta_{0}<p \leq 1\end{cases}
$$

If the seller charges a price less than $\beta_{0}$, the buyer accepts if the 
price is less than his valuation, so the seller's posterior if such a price is refused is that $\beta<\beta_{0}$. This leads the seller to consume in the second period, so that the buyer was correct to accept if the first-period price was below his valuation. If the first price is above $\beta_{0}$, the seller's posterior if the price is refused will also exceed $\beta_{0}$, so the seller would not consume in the second period. This is why $\beta^{*}$ is discontinuous at $p=\beta_{0}$. Given $\beta^{*}(p)$, the seller's best choice is to set $p^{*}=9 / 16<\beta_{0}$.

In the soft-seller equilibrium the seller does not consume in the second period, unless she has charged $p<\tilde{p} \equiv 3 / 4 \beta_{0}+1 / 32<p^{*}$. The price $\tilde{p}$ is chosen so that, if the seller changes $\tilde{p}$, and the buyer expects the seller to make a second offer, the seller's posterior is exactly $\beta_{0}$. The buyer's first-period reservation price in this equilibrium is $\tilde{\beta}(p)$, where

$$
\tilde{\beta}(p)= \begin{cases}p & 0 \leq p \leq \tilde{p} \\ 4 / 3 p-1 / 24 & \tilde{p}<p \leq 1 .\end{cases}
$$

If the seller charges a price above $\tilde{p}$, the seller offers a second price next period, while prices below $\tilde{p}$ lead the seller to consume if the offer is rejected. The equilibrium (optimum) price charged by the seller initially is $p_{0}=\tilde{p}$.

The key difference between the two equilibria is in the buyer's response to first-period prices between $\tilde{p}$ and $\beta_{0}$; in this range, $\beta^{*}(p)=p$, while $\tilde{\beta}(p)>p$. Thus, offers between $\tilde{p}$ and $\beta_{0}$ are comparatively less attractive in the soft equilibrium, and it turns out that the best a soft seller can do is set $p_{0}=\tilde{p}$.

Thus, we see that the seller's choice of whether or not to consume leads to multiple equilibria just as the option of switching does. In models with outside opportunities, multiple equilibria arise because a change in a buyer's beliefs about the seller's toughness can be self-confirming. That is, if starting from an equilibrium, the buyer believes that the seller has become tougher, he himself will become softer. This induces the seller to set a higher price today and, if she is turned down, increases the likelihood that she will consume the good herself tomorrow (in the model where consumption by the seller is allowed). The softer the buyer, the more pessimistic the seller's expectations after a refusal.

In the model without outside opportunities, the seller can, for some beliefs, be indifferent between charging a high price or a lower one. This indifference does not lead to multiple equilibria because it is not self-confirming: refusal by a softer buyer makes the seller 
softer herself, that is, induces her to charge a lower price. Thus, the seller's indifference turns out not to matter, as shown in our earlier paper. The key to that proof was that, despite the freedom to specify different choices for the seller in some subgames, the buyer's reservation price schedule was continuous. With outside offers the reservation price schedule is not continuous, which is "why" there can be multiple equilibria here.

\section{CONCLUSION}

We have seen that a seller can credibly play a take-it-orleave-it strategy when bargaining with many buyers between whom the seller can costlessly switch. Thus, with many "perfectly substitutable" buyers the seller can do as well as if she could precommit herself to a bargaining strategy. If the seller incurs a delay cost in switching negotations to another buyer, then a take-it-or-leave-it strategy need not be credible, and the seller may make several offers to the same buyer before switching. In either case, the equilibrium need not be efficient. Our result contrasts with those of ShakedSutton [1984], who study bargaining with two buyers alternating offers with one seller under complete information. (Actually, they reverse the role of buyers and sellers.) The equilibrium in ShakedSutton is efficient, as would be expected with complete information, so that in particular switching never occurs. Our results highlight the way this conclusion changes when information is incomplete. We have also seen how the possibility that the seller can consume the product herself dramatically changes the nature of the bargaining game if the information is incomplete. If the seller's consumption value were known to be less than that of the buyer, then it would not affect equilibrium play.

UNIVERSiTy OF CALIFornia, BERKELEY

UnIVERSity OF CALIForNia, LOS ANGELES

MASSACHUSETTS INSTITUTE OF TECHNOLOGY

\section{REFERENCES}

Binmore, K., A. Rubinstein, and A. Wolinsky, "The Nash Bargaining Solution in Economic Modelling," mimeo, LSE, 1985.

Bulow, J., "Durable-Goods Monopolists," Journal of Political Economy, XC (1982), 314-32.

Coase, R. H., "Durability and Monopoly," Journal of Law and Economics, XV (April 1972), 143-49.

Fudenberg, D., and J. Tirole, "Sequential Bargaining with Incomplete Information," Review of Economic Studies, L (1983), 221-41. 
Fudenberg, D., D. Levine, and J. Tirole, "Infinite-Horizon Models of Bargaining with One-Sided Incomplete Information," in A. Roth, ed., Game Theoretic Models of Bargaining (Cambridge: Cambridge University Press, 1985a).

Fudenberg, D., D. Levine, and J. Tirole, "Sequential Bargaining with Many Buyers," UCLA mimeo, February $1985 \mathrm{~b}$.

Gul, F., and H. Sonnenschein, "Uncertainty Does Not Cause Delay," mimeo, 1981.

Gul, F., H. Sonnenschein, and R. Wilson, "Foundations of Dynamic Monopoly and the Coase Conjecture," Journal of Economic Theory, XXXIX (1986), 155-90.

Kreps, D., and R. Wilson, "Sequential Equilibria," Econometrica, L (1982), 863-94.

Riley, J., and R. Zeckhauser, "Optimal Selling Strategies: When to Haggle, When to Hold Firm," this Journal, XCVIII (May 1983), 267-88.

Shaked, A., and J. Sutton, "Involuntary Unemployment as Perfect Equilibrium in a Bargaining Model," Econometrica, LII (1984), 1351-64.

Sobel, J., and I. Takahashi, "A Multi-Stage Model of Bargaining," Review of Economics Studies, L (1983), 411-26.

Stokey, N., "Rational Expectations and Durable Goods Pricing," Bell Journal of Economics, XI (Spring 1980), 112-25. 
Copyright of Quarterly Journal of Economics is the property of MIT Press and its content may not be copied or emailed to multiple sites or posted to a listserv without the copyright holder's express written permission. However, users may print, download, or email articles for individual use. 